\title{
Keanekaragaman Semut pada Persawahan di Daerah Urban: Investigasi Pengaruh Habitat Sekitar dan Perbedaan Umur Tanaman Padi
}

\author{
ENRI AGUS SETIANI ${ }^{1}$, AKHMAD RIZALI ${ }^{2,3}$, MOERFIAH ${ }^{1}$, BANDUNG \\ SAHARI $^{2}$, DAN DAMAYANTI BUCHORI ${ }^{3}$ \\ ${ }^{1}$ Program Studi Biologi, Fakultas MIPA, Universitas Pakuan \\ ${ }^{2}$ PEKA Indonesia Foundation, Perumahan IPB Sindang Barang II Bogor \\ ${ }^{3}$ Departemen Proteksi Tanaman, Fakultas Pertanian, Institut Pertanian Bogor
}

(diterima Maret 2010, disetujui Agustus 2010)

\begin{abstract}
Ant Diversity in Rice Field in Urban Landscape: Investigation on the Effect of Habitat Condition and Age of Rice Plant. Agricultural intensification cause negative effect to insect diversity including beneficial insect such as natural enemies and pollinators. Habitat management through habitat heterogeneity is an alternative approach to protect insect diversity in agriculture area. In this study, we investigated the effect of habitat heterogeneity integrated with different age of crop plant in urban agricultural landscape to the ant diversity. The field research was conducted in agricultural area in Carang Pulang Village, Dramaga, Bogor. In around 6 ha area of rice field, grouped into four blocks which each block has different habitat condition and age of rice plant. In bunds of each block were put six pitfall traps with minimum distance 20 meter from each other. Ants were collected weekly from 6 until 12 weeks after planting to standardize the bunds condition. In total 22 species from 4 subfamilies of ants were recorded from this research. Iridomyrmex sp.01 and Odontoponera sp.01 are the common species which always found in each block and in different age of rice plant. There are no correlation between the distance of pitfall traps and similarity of ant species. In addition, habitat conditions surrounding rice field (block) significantly effect to the ant diversity. However, age of rice plant have no effect to the ant diversity.
\end{abstract}

KEY WORDS: Ant diversity, rice field, pitfall trap, habitat heterogeneity

\section{PENDAHULUAN}

Penerapan intensifikasi pertanian memiliki dampak negatif terhadap keanekaragaman serangga khususnya musuh alami dan serangga berguna. Sebagai contoh, penggunaan lahan pertanian menjadi monokultur, menyebabkan penurunan keanekaragaman serangga dan serangga herbivor menjadi dominan (Altieri 1999). Aplikasi pestisida juga mempengaruhi keanekaragaman serangga (Wanger et al. 2010) termasuk musuh alami dan serangga berguna lain seperti polinator (Brittain et al. 2010), serta memicu terjadinya resistensi hama seperti wereng (Matsumura \& Sanada- 
Morimura 2010). Pengurangan pohon naungan dalam sistem budidaya tanaman kakao juga berdampak negatif terhadap keanekaragaman serangga berguna (Klein et al. 2002) termasuk keanekaragaman semut (Wielgoss et al. 2010).

Salah satu upaya meminimalisasi pengaruh negatif intensifikasi pertanian terhadap serangga berguna adalah dengan melakukan manajemen habitat pada lahan pertanian. Diversifikasi habitat melalui sistem polikultur dan pertanian yang ramah lingkungan dapat memfasilitasi keberadaan musuh alami pada suatu lahan pertanian sehingga populasi hama bisa terkontrol secara alami (Altieri 1999). Penyediaan atau pengelolaan habitat alami di sekitar lahan pertanian seperti hutan, juga dapat menjaga keanekaragaman serangga termasuk di dalamnya musuh alami dan serangga berguna lain (Rizali et al. 2002).

Penelitian ini dilakukan untuk mempelajari pengaruh habitat sekitar lahan pertanian di daerah urban terhadap keanekaragaman serangga di dalamnya. Hal ini menarik dilakukan, karena hamparan pertanian (lanskap) di daerah urban merupakan habitat yang sudah tidak alami lagi (terganggu). Sehingga perlu untuk dilakukan investigasi apakah habitat terganggu tersebut memiliki peranan dalam menjaga keanekaragaman serangga yang ada di lahan pertanian.
Semut digunakan sebagai studi kasus dalam penelitian ini karena semut merupakan kelompok serangga yang paling dominan di habitat terestrial (Hölldobler \& Wilson 1990). Disamping itu semut juga memiliki kepekaan terhadap tekanan yang ada di lingkungannya (Andersen 1997, 2000), sehingga dapat digunakan sebagai indikator gangguan habitat (Peck et al. 1998) dan juga indikator pengaruh aplikasi pestisida (Matlock \& de la Cruz 2002). Semut juga bisa beradaptasi dengan manusia atau yang biasa disebut semut tramp (McGlynn 1999) dan bahkan semut Solenopsis geminata mampu beradaptasi pada habitat persawahan mengikuti perubahan kondisi lahan dan umur tanaman padi (Way et al. 1998). Hal inilah yang menjadikan semut sangat sesuai untuk digunakan sebagai studi kasus untuk melihat pengaruh lanskap pertanian di daerah urban terhadap keanekaragaman serangga di dalamnya.

Adapun tujuan dari penelitian ini adalah (1) melakukan eksplorasi keanekaragaman semut pada persawahan di lanskap pertanian daerah urban dan (2) melakukan investigasi mengenai pengaruh kondisi habitat sekitar persawahan dan perbedaan umur tanaman padi terhadap keanekaragaman semut. 


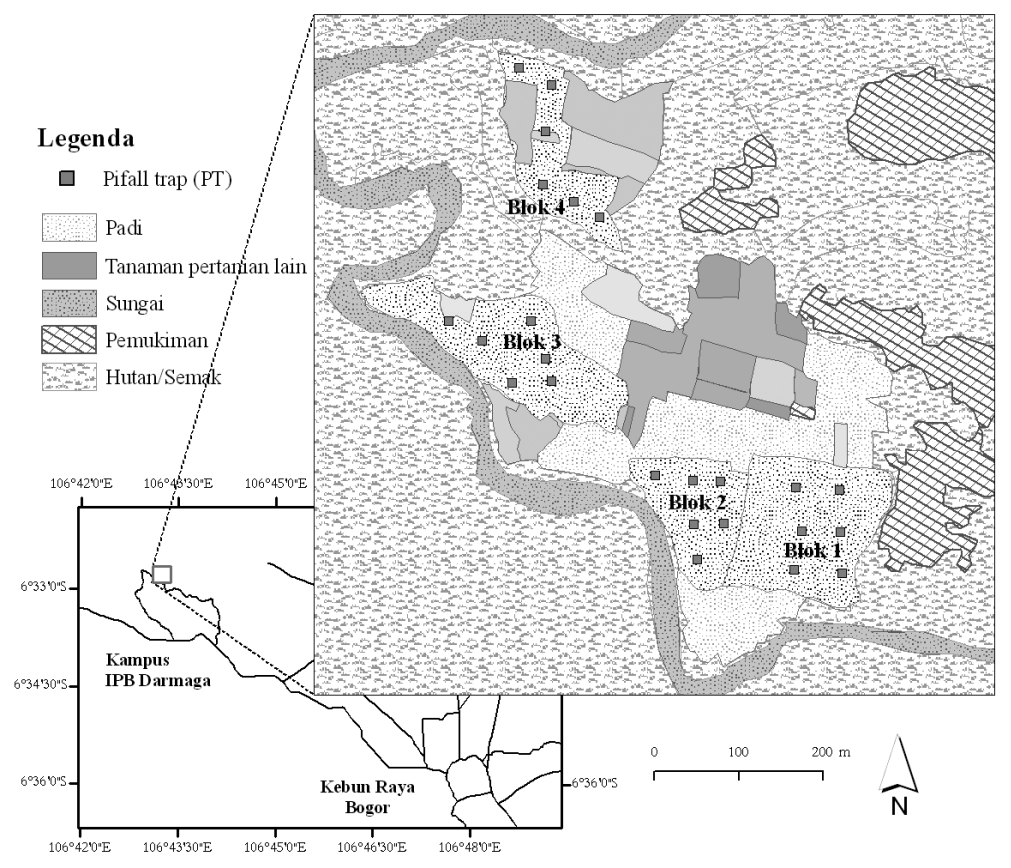

Gambar 1. Lanskap area pertanian di Desa Carang Pulang, Dramaga, Bogor

\section{BAHAN DAN METODE}

\section{Lokasi Penelitian}

Penelitian ini dilaksanakan pada lahan pertanian yang terletak di Desa Carang Pulang, Dramaga, Bogor. Meskipun terletak pada daerah urban, lanskap pertanian di daerah ini tergolong kompleks (heterogen) karena dikelilingi habitat hutan sekunder, kebun, semak, dan sungai (Gambar 1). Sistem pertaniannya termasuk polikultur yaitu walaupun didominasi oleh padi, terdapat juga tanaman pertanian lain seperti singkong, ubi jalar, jagung, bengkoang, dan tanaman palawija. Selain itu cara tanam padi pada area ini tidak serempak, sehingga pada satu hamparan memiliki umur tanaman padi yang berbeda.
Area penelitian dikelompokkan menjadi empat blok berdasarkan pertimbangan keseragaman umur tanaman padi dan perbedaan kondisi habitat sekitar pada setiap blok (Gambar 1). Untuk mendapatkan keanekaragaman semut pada umur padi yang berbeda, di setiap blok dilakukan pengambilan contoh semut pada umur tanaman padi antara 6 hingga 12 minggu setelah tanam (mst). Pemilihan umur tersebut adalah untuk menyeragamkan kondisi pematang (kondisi tanah dan rumput) yang merupakan tempat pemasangan perangkap untuk pengambilan contoh semut. 


\section{Pengambilan Contoh Semut}

Pengambilan contoh semut dilakukan dengan menggunakan perangkap jebak (pitfall) yang merupakan perangkap efektif untuk mengoleksi semut karena bisa menggambarkan kelimpahan individu yang ada pada suatu habitat (Ward et al. 2001). Pada pematang sawah di setiap blok, dipasang enam buah perangkap pitfall dengan jarak minimal 20 meter (Gambar 1). Posisi pemasangan perangkap pitfall ditentukan dengan menggunakan GPS (Global Positioning System), dengan mempertimbangkan keterwakilan terhadap luas lahan di dalam blok tersebut.

Perangkap pitfall yang dipasang berupa gelas plastik berukuran diameter $7.5 \mathrm{~cm}$ dan tinggi $10.5 \mathrm{~cm}$ yang ditanam sejajar dengan permukaan tanah. Gelas plastik selanjutnya diisi dengan air sabun dan dibiarkan selama 24 jam, untuk kemudian dikoleksi semut yang terperangkap di dalamnya. Pemasangan perangkap pitfall dilakukan setiap minggu pada tempat yang sama yaitu mulai umur tanaman padi 6 mst hingga 12 mst. Waktu pengambilan contoh semut ini dilaksanakan dari bulan Juli hingga Oktober 2007.

Seluruh spesimen yang diperoleh dari perangkap disimpan dalam botol plastik berisi alkohol $70 \%$ untuk selanjutnya dilakukan sortir dan identifikasi di laboratorium.

\section{Identifikasi Spesimen Semut}

Seluruh spesimen diidentifikasi sampai tingkat genus dengan mengacu pada Bolton (1994). Setelah itu spesimen diidentifikasi hingga tingkat morfospesies, yaitu pendekatan identifikasi semut hingga tingkat spesies berdasarkan perbedaan karakter dari tiap genus yang ditemukan (Lattke 2000).

\section{Analisis Data}

Untuk mengetahui ada tidaknya hubungan antara jarak pemasangan perangkap pitfall dengan kemiripan spesies semut dilakukan analisis dengan menggunakan uji Mantel (Mantel 1967). Sedangkan analisis kemiripan (analisis of similarity, ANOSIM) digunakan untuk membandingkan keanekaragaman semut antar blok (posisi lahan) dan antar umur tanaman padi yang berbeda. Analisis ragam (analisis of variance, ANOVA) juga digunakan untuk mengetahui faktor yang mempengaruhi keanekaragaman semut. Keseluruhan analisis tersebut dilakukan dengan menggunakan perangkat lunak $R$ Statistic (R Development Core Team 2011).

\section{HASIL DAN PEMBAHASAN}

\section{Keanekaragaman Semut pada Persawahan di Dramaga, Bogor}

Keanekaragaman semut yang ditemukan pada habitat persawahan di Desa Carang Pulang, Dramaga, Bogor, 
Tabel 1. Keanekaragaman semut di setiap blok pengamatan pada persawahan di Desa Carang Pulang, Dramaga, Bogor

\begin{tabular}{|c|c|c|c|c|c|}
\hline \multirow{2}{*}{ Morfospesies } & \multicolumn{4}{|c|}{ Blok } & \multirow{2}{*}{ Total } \\
\hline & 1 & 2 & 3 & 4 & \\
\hline \multicolumn{6}{|l|}{ Dolichoderinae } \\
\hline 1. Iridomyrmex sp.01 & 31 & 94 & 322 & 8 & 455 \\
\hline 2. Tapinoma sp.01 & 4 & 11 & 2 & 9 & 26 \\
\hline \multicolumn{6}{|l|}{ Formicinae } \\
\hline 3. Anoplolepis sp.01 & 122 & 3 & 18 & 87 & 230 \\
\hline 4. Camponotus sp.01 & 3 & & & & 3 \\
\hline 5. Paratrechina sp.01 & 18 & 3 & 12 & 18 & 51 \\
\hline 6. Paratrechina sp.02 & 9 & 4 & 1 & 4 & 18 \\
\hline 7. Polyrhachis sp.01 & & 1 & & & 1 \\
\hline \multicolumn{6}{|l|}{ Myrmicinae } \\
\hline 8. Anillomyrma sp.01 & & & & 1 & 1 \\
\hline 9. Monomorium sp.01 & 4 & & 1 & 3 & 8 \\
\hline 10. Monomorium sp.02 & & 3 & 14 & & 17 \\
\hline 11. Pheidole sp. 01 & 9 & 8 & 33 & 61 & 111 \\
\hline 12. Pheidole sp.02 & 4 & 1 & 2 & & 7 \\
\hline 13. Pheidole sp.03 & & & 418 & & 418 \\
\hline 14. Pheidole sp.04 & & & & 35 & 35 \\
\hline 15. Pheidole sp.05 & & & 5 & & 5 \\
\hline 16. Tetramorium $\mathrm{sp} .01$ & 32 & 4 & & 3 & 39 \\
\hline 17. Tetramorium $\mathrm{sp} .02$ & 1 & & 1 & 1 & 3 \\
\hline 18. Tetramorium sp.03 & & & 3 & & 3 \\
\hline \multicolumn{6}{|l|}{ Ponerinae } \\
\hline 19. Diacamma sp.01 & & & 5 & & 5 \\
\hline 20. Odontomachus sp.02 & 2 & 3 & 10 & & 15 \\
\hline 21. Odontoponera sp.01 & 28 & 6 & 16 & 42 & 92 \\
\hline 22. Ponera sp.01 & & 1 & & & 1 \\
\hline Total & 267 & 142 & 863 & 272 & 1.544 \\
\hline
\end{tabular}

berjumlah 22 spesies dari 4 subfamili (Tabel 1). Spesies Iridomyrmex sp.01, Tapinoma sp.01, Anoplolepis sp.01, Paratrechina sp.01, Paratrechina sp.02, Pheidole sp.01 dan Odontoponera sp.01 merupakan spesiesspesies semut yang memiliki jumlah individu (kelimpahan) tinggi (Gambar 2a) dan selalu ditemukan pada setiap blok (Gambar 2b) serta pada umur tanaman padi yang berbeda (Gambar 2c).
Jumlah individu terbanyak adalah pada spesies Iridomyrmex sp.01 dan ditemukan paling melimpah pada Blok3 (Gambar 2a). Sedangkan spesies Odontoponera sp.01 merupakan spesies semut yang frekuensi ditemukan pada setiap perangkap pitfall lebih sering dibandingkan dengan spesies semut yang lain baik pada tingkat blok 

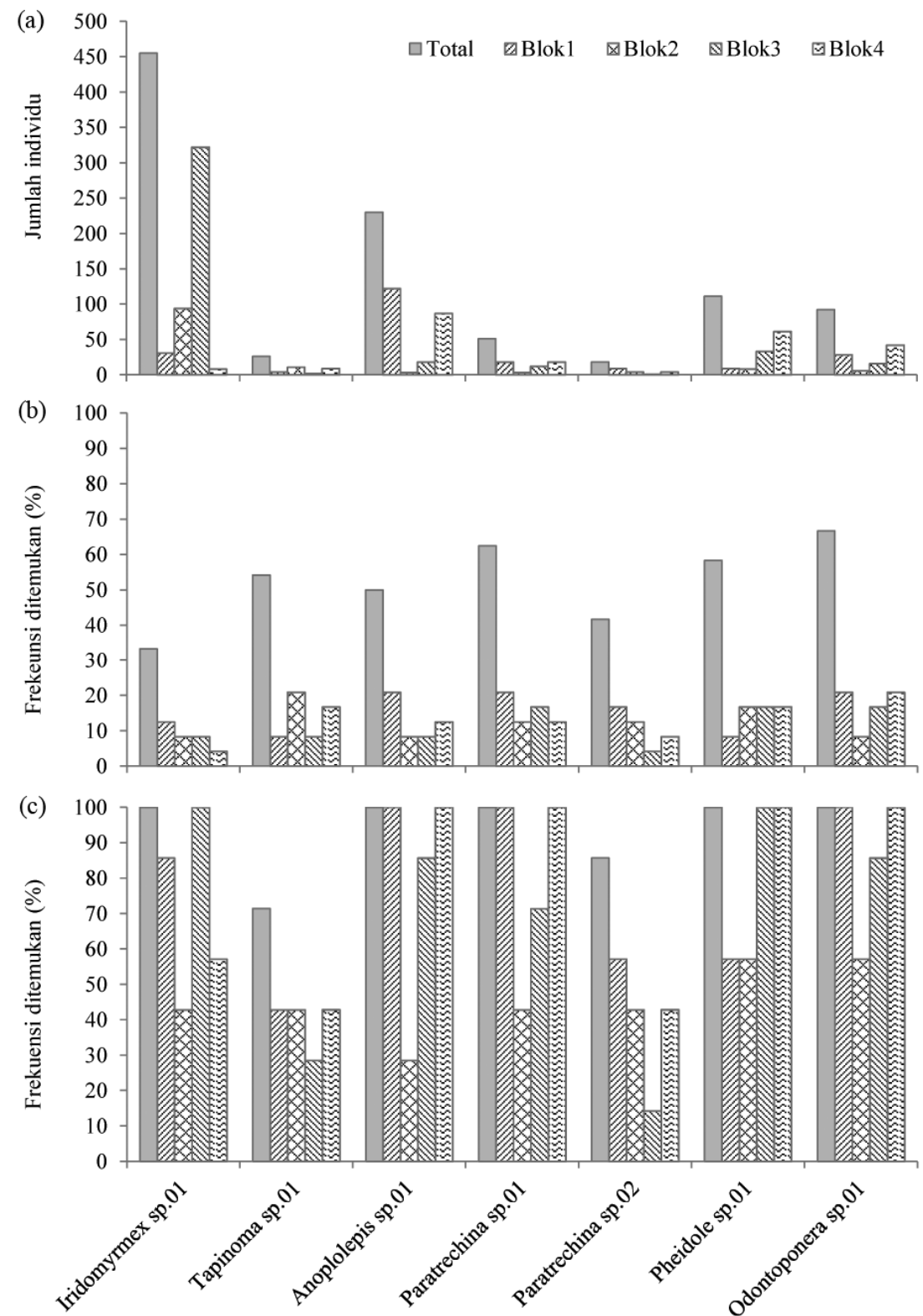

Gambar 2. Kelimpahan individu (a) dan frekuensi ditemukannya spesies semut dominan pada setiap blok (b) dan umur padi berbeda (c) pada persawahan di Desa Carang Pulang, Dramaga, Bogor. Frekuensi ditemukan spesies semut pada setiap blok (b) dihitung dengan: $\mathrm{np} / \mathrm{Np}$ x 100 (np: jumlah perangkap pitfall ditemukannya spesies semut, Np: total perangkap pitfall (24)), sedangkan pada umur padi yang berbeda (c) dengan: $\mathrm{nm} / \mathrm{Nm}$ x 100 (nm: jumlah minggu ditemukan spesies semut, $\mathrm{Nm}$ : total minggu pengamatan (7)) 
maupun keseluruhan lahan persawahan (total) (Gambar 2b). Kedua spesies semut tersebut juga selalu ditemukan pada umur tanaman padi antara $6 \mathrm{mst}$ hingga 12 mst (Gambar 2c).

\section{Pengaruh Posisi Lahan dan Umur Tanaman Padi terhadap Keanekaragaman Semut}

Berdasarkan analisis dengan menggunakan uji Mantel menunjukkan bahwa tidak ada hubungan atau korelasi antara kemiripan spesies semut dengan jarak pemasangan perangkap pitfall $(\mathrm{r}=-0.016, \mathrm{P}=0.58)$, demikian juga pada tingkat blok tidak ada korelasi antara jarak perangkap pitfall di dalam blok dengan kemiripan spesies semut antar perangkap pitfall (Blok1: $\mathrm{r}=0.132, \mathrm{P}=0.36$; Blok2: $\mathrm{r}=$ 0.040, $\mathrm{P}=0.47$; Blok3: $\mathrm{r}=-0.178, \mathrm{P}=$ 0.709; dan Blok4: $\mathrm{r}=0.356, \mathrm{P}=0.09$ ).

Hasil ANOSIM diperoleh bahwa antar blok memiliki kemiripan spesies semut $(\mathrm{R}=0.065, \mathrm{P}=0.17$ ), walaupun demikian berdasarkan ANOVA, posisi lahan (blok) mempengaruhi perbedaan keanekaragaman semut yang ada di dalamnya $\left(\mathrm{F}_{3,18}=6.256, \mathrm{P}=0.004\right)$ (Gambar 3). Sedangkan perbedaan umur tanaman padi, meskipun terjadi fluktuasi keanekaragaman semut pada umur padi yang berbeda (Gambar 4), berdasarkan ANOVA tidak menunjukkan perbedaan keanekaragaman semut $\left(\mathrm{F}_{6,18}=2.040, \mathrm{P}=0.113\right)$.

Keanekaragaman semut pada persawahan di Desa Carang Pulang, Dramaga, Bogor, secara umum hampir sama dengan keanekaragaman semut pada persawahan di daerah lain di Bogor. Spesies yang terkoleksi, umumnya juga ditemukan di persawahan lain walaupun jumlah spesies dari penelitian ini lebih rendah dibandingkan dengan hasil penelitian Rizali et al. (2008) yang menemukan 36 spesies semut. Bahkan pada habitat persawahan di Philipina ditemukan lebih banyak lagi spesies semut yaitu 62 spesies (Way et al. 1998). Perbedaan ini disebabkan oleh letak geografi dan kondisi habitat persawahan yang berbeda, serta metode pengambilan contoh semut yang berbeda pula.

Spesies yang ditemukan di Carang Pulang juga ditemukan pada persawahan lain di Bogor diantaranya Paratrechina, Odontoponera, Tapinoma, Anoplolepis, Pheidole, dan Tetramorium (Rizali et al. 2008). Sedangkan spesies Iridomyrmex tidak ditemukan pada persawahan lain di Bogor. Spesies ini merupakan salah satu spesies yang dominan pada persawahan di Carang Pulang karena ditemukan dalam jumlah individu yang banyak, baik pada blok yang berbeda maupun pada umur tanaman padi yang berbeda. Spesies ini merupakan kelompok dari Subfamili Dolichoderinae yang dominan (Brown 2000) dan keberadaannya pada suatu habitat difasilitasi oleh manusia (Gibb \& Hochuli 2003). Sehingga tidak ditemukan spesies ini di persawahan lain di Bogor, kemungkinan disebabkan oleh 


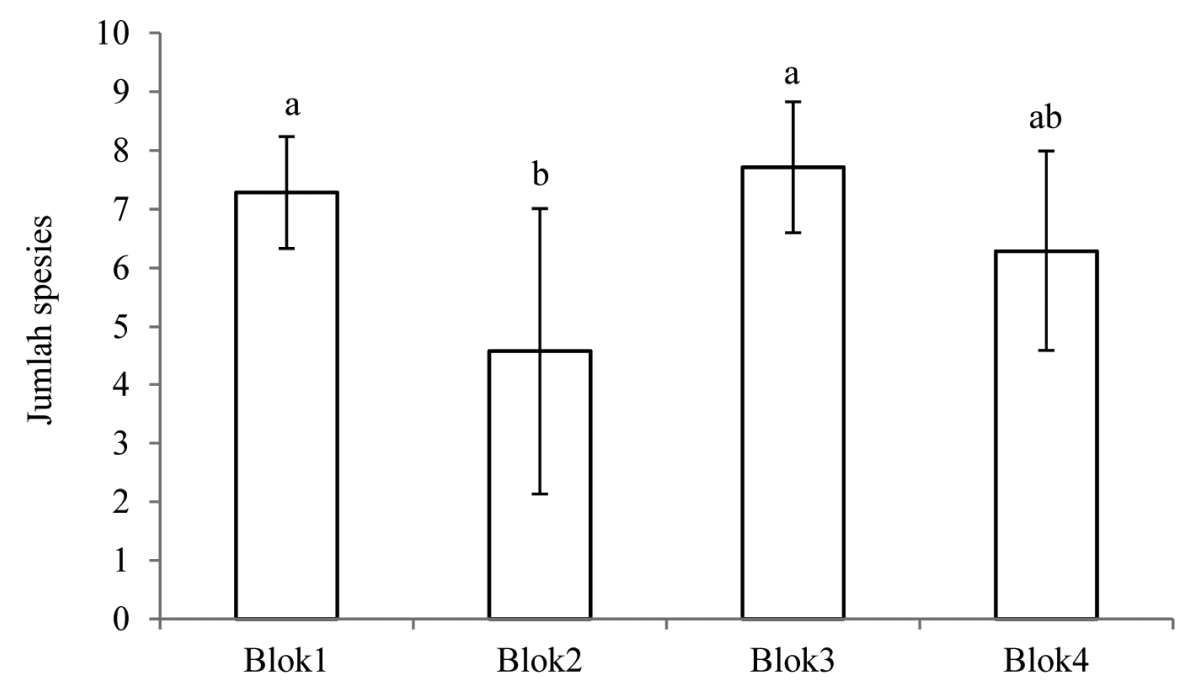

Gambar 3. Perbedaan jumlah spesies semut antar blok $\left(F_{3,18}=6.26, P=0.004\right)$. Huruf yang sama menunjukkan tidak berbeda nyata berdasarkan uji Tukey pada taraf $5 \%$

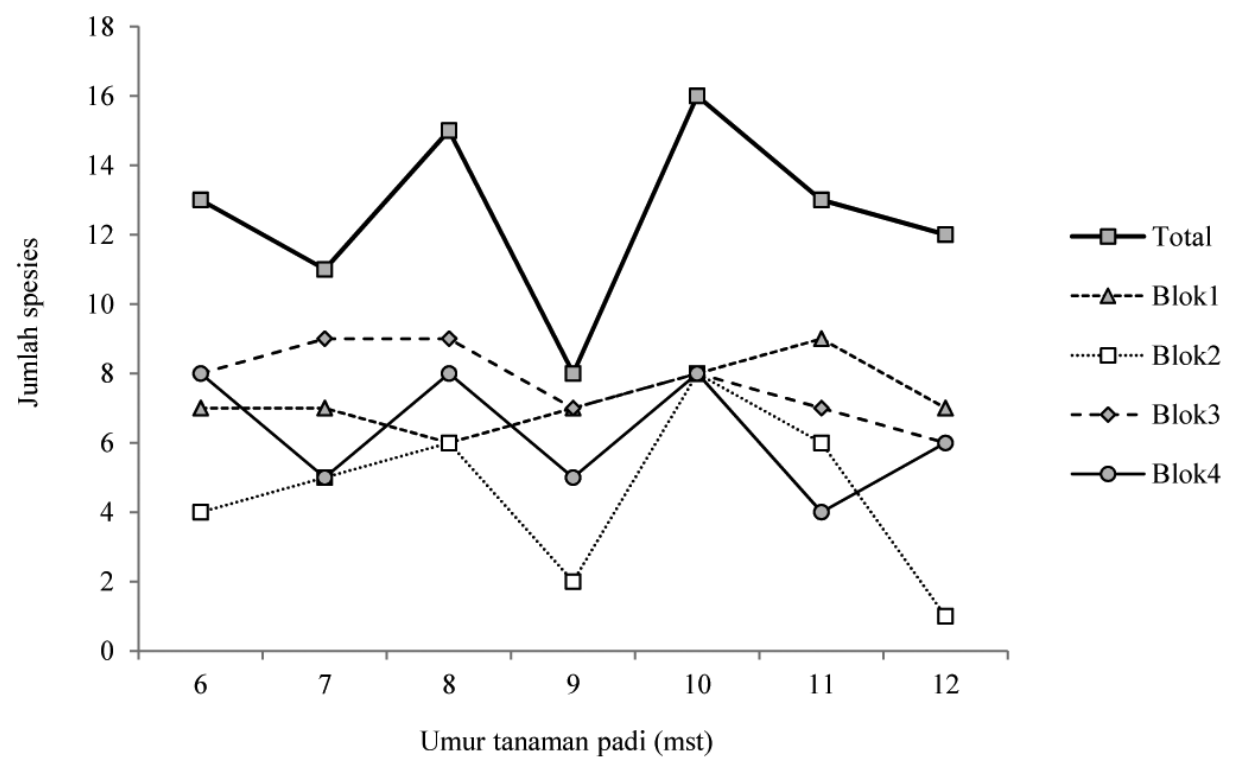

Gambar 4. Fluktuasi keanekaragaman semut pada setiap blok pada umur tanaman padi antara 6 hingga 12 minggu setelah tanam (mst) 
kondisi habitat sekitar persawahan yang berbeda. Di Carang Pulang dengan kondisi habitat yang beragam, diduga merupakan habitat yang sesuai untuk keberadaan semut ini.

Berdasarkan keberadaan spesiesspesies dominan pada setiap blok serta tidak terdapatnya korelasi antara jarak perangkap pitfall dengan kemiripan spesies semut (hasil uji Mantel), meskipun antar blok tidak menunjukkan perbedaan (hasil ANOSIM), menunjukkan bahwa terdapat mosaik semut pada persawahan di Carang Pulang. Hal tersebut karena tidak terjadi tumpang tindih (overlapping) secara spasial antara dua atau lebih spesies semut dominan (Parr \& Gibb 2010). Terdapatnya mosaik semut area tersebut, menunjukkan bahwa pada habitat monokultur bisa terjadi perbedaan keanekaragaman semut selain pada habitat agroforestry seperti kakao (Sanders et al. 2007) ataupun habitat hutan tropis (Blüthgen \& Stork 2007).

Kondisi habitat di sekitar persawahan di Carang Pulang, diduga kuat mempengaruhi keanekaragaman semut yang ada. Perbedaan keanekaragaman semut antar blok menunjukkan bahwa kondisi habitat sekitar blok berperan dalam membentuk komunitas semut yang ada di lahan persawahan di dekatnya. Hal ini sesuai dengan hasil penelitian Settle et al. (1996) bahwa heterogenitas habitat pada lahan persawahan dapat mendukung keberadaan serangga predator termasuk semut.
Habitat alami seperti hutan, juga dapat mempengaruhi keanekaragaman serangga termasuk semut yang ada di persawahan di sekitarnya (Rizali et al. 2002). Selain itu adanya aktivitas manusia di sekitar lahan persawahan juga berperan dalam mendukung ketersediaan pakan bagi semut (Kaspari \& Majer 2000).

Pada penelitian ini, perbedaan umur tanaman padi tidak mempengaruhi perbedaan keanekaragaman semut. Walaupun demikian, terjadi fluktuasi keanekaragaman semut antar umur tanaman padi yang berbeda. Perbedaan umur tanaman padi lebih berhubungan dengan ketersediaan pakan bagi semut, sehingga hanya mempengaruhi kelimpahan tapi bukan keanekaragaman jenis. Hasil penelitian Settle et al. (1996) juga menunjukkan pola yang sama dimana umur tanaman padi mempengaruhi kelimpahan semut dan kelompok predator lain.

Sebagai kesimpulan bahwa habitat persawahan yang heterogen memiliki peranan penting dalam menjaga keanekaragaman serangga berguna khususnya semut walaupun pada lanskap di daerah urban. Hal ini karena keanekaragaman habitat dapat mendukung keberadaan serangga berguna termasuk semut (Altieri 1999). Hasil temuan dari penelitian ini dapat dijadikan sebagai rekomendasi dalam pengelolaan habitat pertanian khususnya dalam aplikasi sistem pertanian organik yang harus mempertim- 
bangkan kondisi habitat di sekitar lahan (Zehnder et al. 2007).

\section{UCAPAN TERIMAKASIH}

Penelitian ini dibiayai oleh SEARCA Seed Fund for Research and Training (SFRT) tahun 2006. Terimakasih kepada Nina Herlina dan Iyus Rahman yang membantu selama pengambilan contoh di lapangan. Kepada reviewer yang telah memberikan masukan untuk perbaikan naskah ini juga kami ucapkan terimakasih.

\section{DAFTAR PUSTAKA}

Altieri MA. 1999. The ecological role of biodiversity in agroecosystems. Agriculture, Ecosystems and Environment 74:19-31.

Andersen AN. 1997. Using ants as bioindicators: multiscale issues in ant community ecology. http:// www.consecol.org/vol1/iss1/art8/. [diakses Maret 2010]

Andersen AN. 2000. Global ecology of rainforest ants: functional groups in relation to environmental stress and disturbance. In: Agosti D, Majer JD, Alonso LE, Schultz TR (ed.), Ants: Standard Methods for Measuring and Monitoring Biodiversity. Washington: Smithsonian Institution Press.

Blüthgen N, Stork NE. 2007. Ant mosaics in a tropical rainforest in Australia and elsewhere: A cri- tical review. Austral Ecology 32: 93-104.

Bolton B. 1994. Identification Guide to the Ant Genera of the World. Cambridge: Harvard University Press.

Brittain C, Bommarco R, Vighi $\mathrm{M}$, Barmaz S, Settele J, Potts SG. 2010. The impact of an insecticide on insect flower visitation and pollination in an agricultural landscape. Agric and Forest Entomol 12:259-266.

Brown WL. 2000. Diversity of ants. In: Agosti D, Majer JD, Alonso LE, Schultz TR (Eds.), Ants: Standard Methods for Measuring and Monitoring Biodiversity. Washington: Smithsonian Institution Press.

Hölldobler B, Wilson EO. 1990. The Ants. Cambridge: Harvard University Press.

Kaspari M, Majer JD. 2000. Using ants to monitor enviromental change. In: Agosti D, Majer JD, Alonso LE, Schultz TR (ed.), Ants: Standard Methods for Measuring and Monitoring Biodiversity. Washington: Smithsonian Institution Press.

Klein A-M, Steffan-Dewenter I, Tscharntke T. 2002. Predator-prey ratios on cocoa along a land-use gradient in Indonesia. Biodivers Conserv 11:683-693.

Lattke JE. 2000. Specimen processing: building and curating an ant 
collection. In: Agosti D, Majer JD, Alonso LE, Schultz TR (ed.), Ants: Standard Methods for Measuring and Monitoring Biodiversity. Washington: Smithsonian Institution Press.

Mantel N. 1967. The detection of disease clustering and a generalized regression approach. Cancer Research 27:209-220.

Matlock RB, Jr., de la Cruz R. 2002. An inventory of Parasitic Hymenoptera in banana plantations under two pesticide regimes. Agric Ecosyst and Environ 93:147-164.

Matsumura M, Sanada-Morimura S. 2010. Recent status of insecticide resistance in asian rice planthoppers. Jarq-Jpn Agr Res $Q$ 44:225230.

McGlynn TP. 1999. The worldwide transfer of ants: geographical distribution and ecological invasions. Biogeography 26:535-548.

Parr CL, Gibb H. 2010. Competition and the role of dominant ants. In: Lach L, Parr CL, Abbott KL (ed.), Ant Ecology. New York: Oxford University Press.

Peck SL, Mcquaid B, Campbell CL. 1998. Using ant species (Hymenoptera: Formicidae) as a biological indicator of agroecosystem condition. Environ Entomol 27: 1102-1110.

R Development Core Team. 2011. R: A language and environment for statistical computing. R Foundation for Statistical Computing, Vienna, Austria.

Rizali A, Bos MM, Buchori D, Yamane S, Schulze CH. 2008. Ants in tropical urban habitats: the myrmecofauna in a densely populated area of Bogor, West Java, Indonesia. HAYATI Biosciences 15:77-84.

Rizali A, Buchori D, Triwidodo $\mathrm{H}$. 2002. Keanekaragaman serangga pada lahan persawahan-tepian hutan: indikator untuk kesehatan lingkungan. HAYATI Biosciences 9:41-48.

Sanders NJ, Crutsinger GM, Dunn RR, Majer JD, Delabie JHC. 2007. An ant mosaic revisited: dominant ant species disassemble arboreal ant communities but co-occur randomly. BIOTROPICA 39:422427.

Settle WH, Ariawan H, Astuti ET, Cahyana W, Hakim AL, Hindayana D, Lestari AS, Pajarningsih, Sartanto. 1996. Managing tropical rice pests through conservation of generalist natural enemies and alternative prey. Ecology 77: 1975-1988.

Wanger TC, Rauf A, Schwarze S. 2010. Pesticides and tropical biodiversity. Frontiers in Ecol Environ 8:178-179.

Ward DF, New TR, Yen AL. 2001. Effects of pitfall trap spacing on the abundance, richness and 
composition of invertebrate catches. J Insect Conservation 5:4753.

Way MJ, Islam Z, Heong KL, Joshi RC. 1998. Ants in tropical irrigated rice: distribution and abundance, especially of Solenopsis geminata (Hymenoptera: Formicidae). Bull. Entomol. Res. 88:467-476.

Wielgoss A, Tscharntke T, Buchori D, Fiala B, Clough Y. 2010. Temperature and a dominant dolicho- derine ant species affect ant diversity in Indonesian cacao plantations. Agric Ecosyst \& Environ 135:253-259.

Zehnder G, Gurr GM, Kühne S, Wade MR, Wratten SD, Wyss E. 2007. Arthropod pest management in organic crops. Ann Entomol 52:57-80. 